\title{
EFFECTS OF MULCHING WITH VINEYARD AND WINERY WASTE ON SOIL FUNGI AND BOTRYTIS BUNCH ROT IN MARLBOROUGH VINEYARDS
}

\author{
D.C. MUNDY and R.H. AGNEW \\ The Horticulture and Food Research Institute of New Zealand, Private Bag \\ 1007, Blenheim \\ Corresponding author:dmundy@hortresearch.co.nz
}

\begin{abstract}
Field trials were established in four vineyards in January 1999 to evaluate the effects of four mulch mixtures containing vineyard and winery wastes, on different soil and plant parameters. The effect of mulch treatment on numbers of colony forming units of soil fungi was assessed using soil dilution plating. During 3 years (1999-2002) the numbers of soil fungi tended to be higher in soil sampled from under mulch-treated plots than in soil from non-mulched plots. The effect of mulches on incidence and severity of botrytis bunch rot (caused by Botrytis cinerea) was also investigated. Incidence of the disease was not increased by the mulch treatments, and in some instances bunch rot incidence was less on grapes from mulched plots than un-mulched plots.

Keywords: soil fungi, sustainable viticulture, mulch, botrytis bunch rot.
\end{abstract}

\section{INTRODUCTION}

To improve the sustainability of winegrape production, it has been suggested that vineyard and winery waste could be incorporated into mulches for use in vineyards, rather than dumping it off-site. The potential benefits from using mulches include nutrient release, increased soil organic matter and improved soil structure as a result of aggregate formation by soil fungi.

In other cropping systems mulch application increased microbial activity and biomass in soil (Manna et al. 2001) and reduced the severity of some above ground diseases of plants in crops such as tomatoes (Abbasi et al. 2002). We have previously reported effects of winery waste mulch on soil moisture, soil nutrients, soil organic matter and crop yield in grapes (Agnew et al. 2001; Mundy \& Agnew 2002).

Botrytis bunch rot is the major disease problem in wine grape production. This disease can overwinter on dormant canes and trash on the surface of vineyard soil. It is therefore possible that mulches containing grapevine prunings might act as sources of inoculum in vineyards and increase the risk of yield losses from botrytis bunch rot. In this paper we present information from a 3 year study on the effects of winery waste mulch on vineyard fungi and on botrytis bunch rot.

\section{METHODS}

Field trials were established at four Marlborough vineyard sites in January 1999 using grafted Sauvignon Blanc vines that were at least 5 years old. All of the vines were grown on commercial properties under standard vineyard practices. Some differences in leaf plucking, irrigation timing and other management practices existed between sites. Different waste streams were used to produce four mulches (Table 1) that had Carbon:Nitrogen ratios from 21-28. Mulched plots were compared with bare soil control plots in a randomised block design with six replicates per treatment. The mulch treatments were applied at a thickness of $15 \mathrm{~cm}$ in a $75 \mathrm{~cm}$ wide strip 
under the vines with no replenishment during the trial. Trial plots at different sites ranged from 5.5 to $7.5 \mathrm{~m}$ in length and contained three or four plants depending on the site.

During the 1999/2000 season all trial sites received a standard fungicide spray programme which included botryticides. No botryticides were applied during the 2000/ 2001 or 2001/2002 growing seasons.

Results were analysed using the Minitab Inc. statistical package with each site and season analysed separately. General Linear Model procedure was used, with Dunnett simultaneous tests to compare each of the treatment means with the experimental control.

Assays of soil fungi

Soil samples were collected to $10 \mathrm{~cm}$ depth in November each year from each of the four sites for micro-organism extraction and recording of soil weight. For each sample, the shaken soil solution of $40 \mathrm{~g}$ of soil in $100 \mathrm{ml}$ of sterile distilled water was serially diluted to $10^{-6}$ with distilled water and plated onto media. The media used were Potato Dextrose agar (Oxoid LTD, Basingstoke, Hampshire, England), Malt Extract Agar (Remael, Lenexa, KS) and Nutrient Broth (Life Technologies, Paisley, Scotland) solidified with 23.5 g/litre of Standard Methods Agar (Life Technologies, Paisley, Scotland). Counts of micro-organisms were conducted after a week of incubation at $20^{\circ} \mathrm{C}$ under continuous light. From these counts the mean number of fungi/g soil was calculated.

Assessment of bunch rot

Botrytis bunch rot was assessed at harvest on ten bunches from opposite sides of each plot, giving 20 bunches per plot and 120 bunches per treatment from each trial. Severity of infection was recorded as the percentage of berries in each bunch that had visible sporulating $B$. cinerea. To reduce visual assessment errors (Emmett et al. 1997), disease was assessed by the same two trained assessors at all sites in all seasons.

TABLE 1: Percentage (by volume) of waste stream components in each mulch treatment applied to vineyard soils.

\begin{tabular}{lcccccc}
\hline & $\begin{array}{c}\text { Vineyard } \\
\text { prunings }\end{array}$ & Marc & $\begin{array}{c}\text { Green } \\
\text { waste }\end{array}$ & Pine Bark & $\begin{array}{c}\text { Animal } \\
\text { manure }\end{array}$ & $\begin{array}{c}\text { Mussel } \\
\text { shells }\end{array}$ \\
\hline Mulch 1 & $36 \%$ & $18 \%$ & $46 \%$ & 0 & 0 & 0 \\
Mulch 2 & $27 \%$ & $13 \%$ & $34 \%$ & $26 \%$ & 0 & 0 \\
Mulch 3 & $25 \%$ & $12 \%$ & $32 \%$ & $25 \%$ & $6 \%$ & 0 \\
Mulch 4 & $23 \%$ & $12 \%$ & $30 \%$ & $23 \%$ & $6 \%$ & $6 \%$ \\
\hline
\end{tabular}

\section{RESULTS}

Soils from the mulch-treated plots had similar or higher mean numbers of fungal colony forming units compared to the non-mulched plots (Table 2). Of the mulch types tested, Mulch 4 tended to give greater numbers of soil fungi across a number of sites and in different years.

The use of mulches did not consistently increase or decrease the level of Botrytis bunch rot present. There were no instances where the presence of mulch significantly increased the level of Botrytis bunch rot. However there were some instances where the presence of mulch reduced $(\mathrm{P}<0.05)$ incidence of the disease (Table 3$)$. Usually, where disease incidence was reduced by the mulch treatments, bunch rot severity was also reduced $(\mathrm{P}<0.05$; data not presented). 
TABLE 2: Mean numbers of fungal colony forming units (millions/g soil) at four sites in different years where different mulch treatments had been applied.

\begin{tabular}{lcccccc}
\hline \multirow{2}{*}{ Site } & Year & Mulch 1 & Mulch 2 & Mulch 3 & Mulch 4 & No Mulch \\
\hline \multirow{2}{*}{ Brancott } & 2000 & 21.3 & 38.8 & 66.6 & $101.3^{* 1}$ & 33.7 \\
& 2001 & 27.1 & $72.6^{*}$ & $51.8^{*}$ & 29.1 & 3.3 \\
\multirow{3}{*}{ Stoneleigh } & 2002 & $179.1 *$ & 94.4 & 40.8 & 61.8 & 21.6 \\
& 2000 & 49.6 & 43.9 & 18.6 & 15.8 & 33.5 \\
\multirow{3}{*}{ Matador } & 2001 & 23.2 & 9.5 & 43.0 & 70.6 & 58.2 \\
& 2002 & 29.5 & 31.2 & 11.9 & $36.5^{*}$ & 5.9 \\
\multirow{2}{*}{ Cloudy Bay } & 2000 & 65.7 & 59.0 & 71.8 & $98.5^{*}$ & 28.1 \\
& 2002 & 22.8 & 29.9 & $67.4^{*}$ & $72.6^{*}$ & 14.6 \\
& 2000 & 28.6 & 58.2 & 18.2 & 31.5 & 34.8 \\
& 2001 & 6.6 & $78.8^{*}$ & 30.2 & $103.5^{*}$ & 17.2 \\
& 2002 & $92.6^{*}$ & 55.5 & $105.9 *$ & $122.5^{*}$ & 59.5 \\
& & 54.0 & 68.1 & 57.7 & 28.8 \\
\hline
\end{tabular}

${ }^{1}$ Means of each mulch treatment in each year were compared to the no mulch treatment using a single factor ANOVA.

* indicates means that are different $(\mathrm{P}<0.05)$ to the no mulch treatment.

TABLE 3: Mean percentage incidence of Botrytis bunch rot on grape bunches from different sites and in different years from plots to which different mulch treatments had been applied.

\begin{tabular}{lcccccc}
\hline \multirow{2}{*}{ Site } & Year & Mulch 1 & Mulch 2 & $\begin{array}{r}\text { Treatment } \\
\text { Mulch 3 }\end{array}$ & Mulch 4 & No Mulch \\
\hline Brancott & 2000 & 1 & $0^{* 1}$ & 1 & $0 *$ & 1 \\
& 2001 & $0^{*}$ & $0^{*}$ & 2 & 1 & 2 \\
Stoneleigh & 2002 & 25 & $12^{*}$ & $11 *$ & 30 & 28 \\
& 2000 & 23 & $19^{*}$ & 22 & 24 & 25 \\
\multirow{5}{*}{ Matador } & 2001 & $10^{*}$ & 15 & 13 & 12 & 13 \\
& 2002 & 3 & 8 & 8 & 8 & 4 \\
\multirow{5}{*}{ Cloudy Bay } & 2000 & 47 & 48 & 58 & $34^{*}$ & 40 \\
& 2001 & 1 & 5 & 8 & 5 & 3 \\
& 2002 & 29 & $18^{*}$ & 25 & 25 & 28 \\
& 2001 & 1 & 0 & 3 & 1 & 1 \\
& 2002 & 14 & 11 & 13 & 22 & 13
\end{tabular}

${ }^{1}$ Means of each mulch treatment in each year were compared to the bare soil control using a single factor ANOVA.

* indicates means that are different $(\mathrm{P}<0.05)$ to the no mulch treatment. 


\section{DISCUSSION}

Increased numbers of fungi occurred in vineyard soils to which mulch treatments had been applied. Commonly used non-selective methods for the isolation of soil fungi (Gams et al 1998) include taxonomic identification of the fungal species present. During this investigation identification was not conducted. The aim of our study was to determine if changes in soil fungal populations were occurring rather than to measure the detailed nature of any change. However, taxonomic identification of the species present would have been useful. To date published research on the effects of mulches on soil fungi in grape production is lacking, both within New Zealand and internationally. Now that we have detected changes in the total numbers of fungi present in mulched soils, other methods, such as direct observation of grape roots for mycorrhizal fungi, are being used to determine if the changes in soil are beneficial for the grape vines.

Mulch containing grape prunings did not increase severity of botrytis bunch rot on grapevines compared to the bare soil experimental control treatment. This result is consistent with previous investigations demonstrating that almost all mulch samples were free of $B$. cinerea (Mundy \& Agnew 2001), despite the potential of grape prunings to support the carry-over of $B$. cinerea inoculum between seasons.

Seasonal differences and site management probably had a greater effect on disease levels in the vineyards than the mulch treatments. The 2000/2001 season in Marlborough was very dry. In 2001/2002, severity of botrytis bunch rot was lower even with less use of fungicides, probably because $B$. cinerea inoculum was less as a result of the previous dry season.

Following 3 years of investigation at four sites we conclude that under the conditions investigated, these mulches had only minor effects on incidence and severity of botrytis bunch rots on grapevines.

\section{ACKNOWLEDGEMENTS}

Funding was provided by The Ministry for the Environment (SMF project 4123).

\section{REFERENCES}

Abbasi, P.; Al-Dahmani, J.; Sahin, F.; Hoitink, H.A.J.; Miller, S.A.; 2002: Effect of Compost Amendments on Disease Severity and Yield of Tomato in Conventional and Organic Production Systems. Plant Disease 86(2): 156-161.

Agnew, R.; Mundy, D.; Fitzgerald, C.; Hill, R.A.; Spiers, M.; Reglinsky, T.; Clothier, B.; McDonald, A.; Wheeler, M.; 2001: SMF Project 4123 Wastestream utilisation for sustainable viticulture - Annual Report 2000/2001. HortResearch Client Report No. 2001/327. 41 p.

Emmett, B.; Magarey, P.; Nutter, F.Jnr.; 1997: Assessing damage from grapevine diseases and pests. The Australian Grapegrower \& Winemaker, Annual Technical Issue: 4952.

Gams, W.; 1998. The study of ecological groups of fungi and applied aspects. In Gams, W.; Hoekstra, E.S.; Aptroot, A. ed. CBS Course of Mycology. Ponson \& Looyen, Wageningen. Pp. 106-119.

Manna, M.C.; Ghosh, P.K.; Ghosh, B.N.; Singh, K.N. 2001: Comparative effectiveness of phosphate-enriched compost and single superphosphate on yield, uptake of nutrients and soil quality under soybean-wheat rotation. J. Agric. Sci. 137: 45-54.

Mundy, D.; Agnew, R.; 2002: Grape marc in mulches: the potassium effect. The Australian and New Zealand Grapegrower and Winemaker, March: 59-62. 